\title{
Cardioprotective effect of preconditioning is more efficient than postconditioning in rats submitted to cardiac ischemia and reperfusion ${ }^{1}$
}

José Gustavo Padrão Tavares', Paolo Ruggero Errante", Tânia Carmem Peñaranda Govato"I, Ênio Rodrigues Vasques ${ }^{\mathrm{IV}}$, Renato Ribeiro Nogueira Ferraz ${ }^{\mathrm{V}}$, Murched Omar Tahav', Francisco Sandro Menezes-Rodrigues ${ }^{\mathrm{VII}}$, Afonso Caricati-Neto ${ }^{\mathrm{VIII}}$

'Fellow PhD degree, Postgraduate Program in Pharmacology, Universidade Federal de São Paulo (UNIFESP), Brazil. Conception and design of the study, analysis and interpretation of data, manuscript writing.

"Fellow PhD degree, Postgraduate Program in Pharmacology, UNIFESP, Sao Paulo-SP, Brazil. Analysis and interpretation of data, manuscript writing.

'"'Assistant Professor, Department of Pharmacology, Faculdade de Medicina do ABC (FMABC), Santo Andre-SP, Brazil. Statistical analysis.

IVFellow PhD degree, Department of Gastroenterology, Faculty of Medicine, Universidade de São Paulo (USP), Brazil. Interpretation of electrocardiogram.

${ }^{\vee}$ Full Professor, Program in Management of Health System (PMPA-GSS), Universidade Nove de Julho (UNINOVE), Sao Paulo-SP, Brazil. Critical revision.

${ }^{V 1}$ Associate Professor, Department of Surgery, UNIFESP, Sao Paulo-SP, Brazil. Technical procedures.

VIIFellow PhD degree, Postgraduate Program in Pharmacology, UNIFESP, Sao Paulo-SP, Brazil. Critical revision.

VIIIAssociate Professor, Department of Pharmacology, UNIFESP, Sao Paulo-SP, Brazil. Conception and design of the study, critical revision.

\section{Abstract}

Purpose: To investigate the cardioprotective effects of ischemic preconditioning (preIC) and postconditioning (postIC) in animal model of cardiac ischemia/reperfusion.

Methods: Adult rats were submitted to protocol of cardiac ischemia/reperfusion (I/R) and randomized into three experimental groups: cardiac I/R ( $n=33)$, preCl + cardiac I/R $(n=7)$ and postCl + cardiac I/R ( $n=8)$. After this $I / R$ protocol, the incidence of ventricular arrhythmia (VA), atrioventricular block (AVB) and lethality (LET) was evaluated using the electrocardiogram (ECG) analysis.

Results: After reestablishment of coronary blood flow, we observed variations of the ECG trace with increased incidence of ventricular arrhythmia (VA) (85\%), atrioventricular block (AVB) (79\%), and increase of lethality (70\%) in cardiac I/R group. The comparison between I/R + prelC group with I/R group demonstrated significant reduction in VA incidence to $28 \%$, AVB to $0 \%$ and lethality to $14 \%$. The comparison of I/R + post IC group with I/R group was observed significance reduction in AVB incidence to $25 \%$ and lethality to $25 \%$.

Conclusion: The preconditioning strategies produce cardioprotection more efficient that postconditioning against myocardial dysfunctions and lethality by cardiac ischemia and reperfusion.

Key words: Myocardial Infarction. Myocardial Reperfusion Injury. Ischemic Preconditioning, Myocardial. Ischemic Postconditioning. Rats. 


\section{Introduction}

The coronary reperfusion therapy constitutes the major therapeutic strategy to salvage the myocardium from tissue injury following prolonged ischemia in acute myocardial infarction (AMI) patients ${ }^{1-3}$. However, the beneficial effect of this therapy is compromise by myocardial injuries caused during coronary reperfusion that subsequently lead to cardiac dysfunctions, including arrhythmias, caused by bioenergetic and electrochemical misbalance caused mainly by reduction of ATP production by mitochondria and cytosolic $\mathrm{Ca}^{2+}$ overload in cardiomyocytes ${ }^{4,5}$.

Strategies to limit myocardial damage in acute myocardial infarction include, in addition to early reperfusion, the improvement of the endogenous resistance of cardiac cells to blood deprivation, which can be obtained by stimulating its survival mechanisms that function as a molecular adaptation to ischemic stress $^{2}$. Among these phenomena, we can mention the stunned and the hibernation of the myocardium. Stunned is defined as a prolonged and reversible ischemic heart dysfunction, which persists after reperfusion, despite normalization of blood flow ${ }^{6}$.

The hibernating myocardium represents a condition in which a prolonged sub-acute or chronic state of myocardial ischemia results in a new equilibrium in which myocardial necrosis does not settle because the metabolism and function are reduce proportionally to the concomitant reduction of coronary flow? ${ }^{7}$. Other phenomena described are myocardial pre and postconditioning ${ }^{8}$. Ischemic preconditioning (pre $\mathrm{Cl}$ ) describes the protection afforded by brief period (or periods) of ischemia against a later ischemic episode of longer duration. This protection is typically measure as prevention against arrhythmias, reduction in myocardial infarction size or better recovery of the electrical and contractile function of the heart ${ }^{9}$.
The main advantages of preCl are in fact this can be inducing by ischemia or directly in heart, can be programme in case of surgery or angioplasty, situations where heart function is compromise. The preCl has cardioprotective efficacy of two periods with different characteristics: the first window of protection (preCl early) is more effective in reducing the extent of infarct size, and the second window of protection (preCl late) is most effective against myocardial stunning ${ }^{10}$. Ischemic postconditioning consists of alternating brief periods of reperfusion and brief reocclusions applied in the initial minutes of reperfusion ${ }^{11}$. In ischemic postconditioning (postCl), is necessary to make brief mechanical interruptions of reperfusion early in process. The mechanisms by which postCl confers cardioprotection in cardiac $\mathrm{I} / \mathrm{R}$ resemble those of preCl, and adenosine has been implicate in the cardioprotective effect conferred by postCl, since inhibitors of the action of adenosine inhibit this effect ${ }^{12}$. PostCl that is more clinically applicable than preconditioning, once your application occurs before an ischemic episode, but at the time of reperfusion. In this study aims to characterize the ECG changes caused by I/R cardiac process and quantify the incidence of lethality in animals subjected to $\mathrm{I} / \mathrm{R}$ and evaluate the effectiveness of $\mathrm{preCl}$ and postCl.

\section{Methods}

All experimental procedures were approved by Ethical Committee, UNIFESP (\#1130/11).

Forty eight adult (14 - 16 week-old, 300 to $340 \mathrm{~g}$ ) male Wistar rats were maintained under standard conditions of nutrition, hydration, temperature, humidity and light/ dark cycle. Rats were submitted to cardiac I/R and randomized into three groups: cardiac $\mathrm{I} / \mathrm{R}$ $(n=33)$, preCl + cardiac $I / R(n=7)$ and postCl + cardiac $\mathrm{l} / \mathrm{R}(\mathrm{n}=8)$. 


\section{Protocol of cardiac ischemia and reperfusion (I/R)}

All experimental procedures used to induce cardiac $\mathrm{l} / \mathrm{R}$ in this study were previously described in other studies published by our ${ }^{l a b^{13,14}}$. After anesthesia with urethane (1.25 $\mathrm{g} / \mathrm{kg}$ ), rats were submitted to orotracheal intubation and adapted in mechanical ventilator apparatus (Insight, model EFF 312, Brazil) with room air (volume of $10 \mathrm{~mL} / \mathrm{kg}$ and 70 breaths $/ \mathrm{min}$ ). The body temperature was maintained at $37.5 \circ \mathrm{C}$ with a heated operating platform and appropriate heating lamps, and was evaluated routinely via a rectal thermometer. After this procedure, the chest was opened with a left thoracotomy between fourth and fifth intercostal space to exteriorization of heart using mechanical pressure on the abdomen. To induce ischemia, surgical tourniquet (Mononylon Ethilon 5.0, Atramac, Mexico) attached to a $10-\mathrm{mm}$ micro point reverse-cutting needle was placed around the left anterior descending coronary artery (about $2 \mathrm{~mm}$ from its origin). The two ends of nylon silk yarn were passed inside a cylindrical tube of polypropylene to perform a surgical tourniquet. After stabilization for $15 \mathrm{~min}$, this tourniquet was tied for mechanical occlusion of coronary (ischemia). After 10 min of occlusion, the nylon tourniquet was removed to allow coronary recirculation (reperfusion) during 120 $\min$.

\section{ECG analysis}

To evaluate cardiac electrical activity, the ECG system was adapted in rats submitted to cardiac I/R. Cardiac electrical activity were measured during $10 \mathrm{~min}$ ischemia and $120 \mathrm{~min}$ reperfusion ${ }^{13,14}$. The ECG was recorded from the beginning of the stabilization period using a data acquisition system (AqDados 7.02; Lynx Tecnologia Ltda, Brazil). The recorded raw data was analysed using the computer program (AqDAnalysis 7, Lynx Tecnologia Ltda, Brazil).
Incidence of $\mathrm{VA}, \mathrm{AVB}$, and LET in response to cardiac $\mathrm{I} / \mathrm{R}$ were evaluated by ECG analysis. To simplify the presentation of the results, ventricular fibrillation, torsades de pointes, and ventricular tachycardia parameters were considered only as VA. ECG measurements were evaluated according to Lambeth conventions ${ }^{13,14}$.

\section{Protocol of preconditioning and posconditioning}

The cardiac $1 / R$ group $(n=33)$ was proposed to analyze and establish the amendments ECG and mortality of animals submitted to I/R. In the preCl + I/R was studied the effect of 3 short cycles of ischemia lasting $3 \mathrm{~min}$ and $5 \mathrm{~min}$ intervals between I/R cycles, applied before performing longer duration of ischemia (10 $\mathrm{min})$. In the cardiac I/R group treated with postCl $+\mathrm{I} / \mathrm{R}$, ischemia held 3 cycles of 1 min interspersed with 3 cycles of 3 min of reperfusion.

\section{Statistical analysis}

The incidence of $V A, A V B$, and LET was compared by the Fisher's exact test. Values were considered significant to $p<0.05$. Statistical analyses were performed by Prism 5.0 software (GraphPad, USA), and data were expressed as means $\pm \mathrm{SE}$.

\section{Results}

Cardiac I/R group showed changes in the ECG tracing from the 5 minutes of first ischemic arrhythmias corresponded to VA (ventricular extra systoles, ventricular tachycardia and torsade de pointes) and AVB in most animals tested occurred, and the rest of animals tested showed no arrhythmias during ischemia. Very few animals died because of arrhythmias during cardiac ischemia (data not showed).

After reestablishment of coronary blood flow by removing wire Nylon variations 
of ECG trace, with increased incidence of VA (85\%), AVB (79\%) and mortality (70\%) were observed (Figure 1). In animals that had no arrhythmias during ischemia, the arrhythmic events began to occur during reperfusion; no deaths were observed during first four minutes of reperfusion, but between 5th and 20th minutes of reperfusion.

The Figure 1 also shows that the preCl significantly reduced the incidence of cardiac arrhythmias (VA and AVB) and mortality. The comparison of group I/ $R+$ preCl with I/R group showed significant reduction in $\mathrm{VA}$ incidence to $28 \%$, AVB to $0 \%$ and mortality to $14 \%$.

Figure 2 shows that the postCl significantly reduced incidence of $A V B$ and mortality but not VA. The comparison of group $\mathrm{I} / \mathrm{R}+$ postCl with I/R group showed significant reduction in incidence of $A V B$ and mortality for $25 \%$.
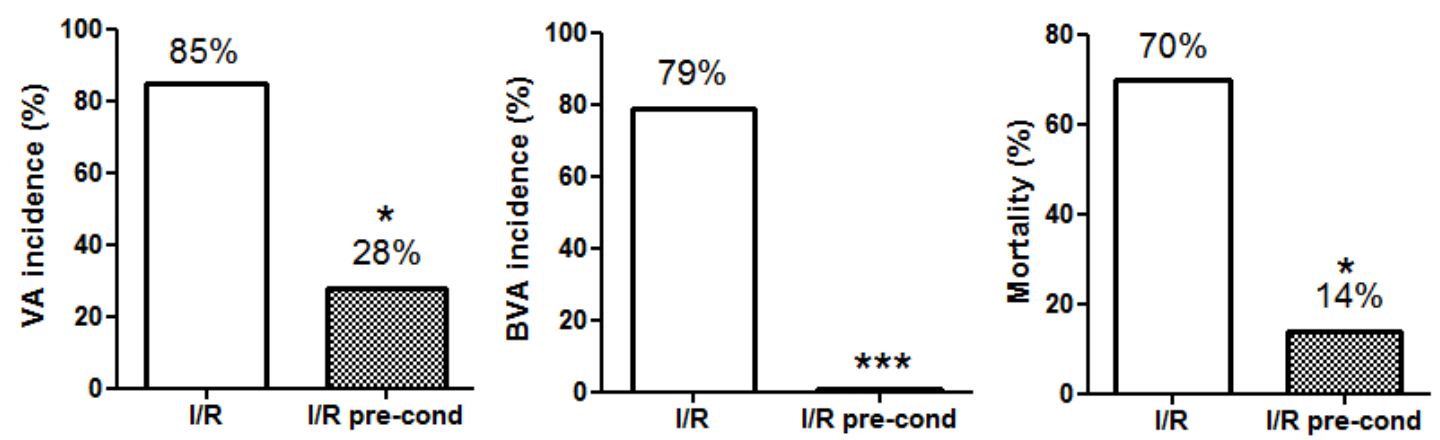

Figure 1 - Histograms representing percentages of VA, BVA and mortality incidence in groups I/R and I/R + preCl. Statistical analysis were performed from Fisher's exact test $\left({ }^{*} p<0.05, * * * p<0.0005\right)$.
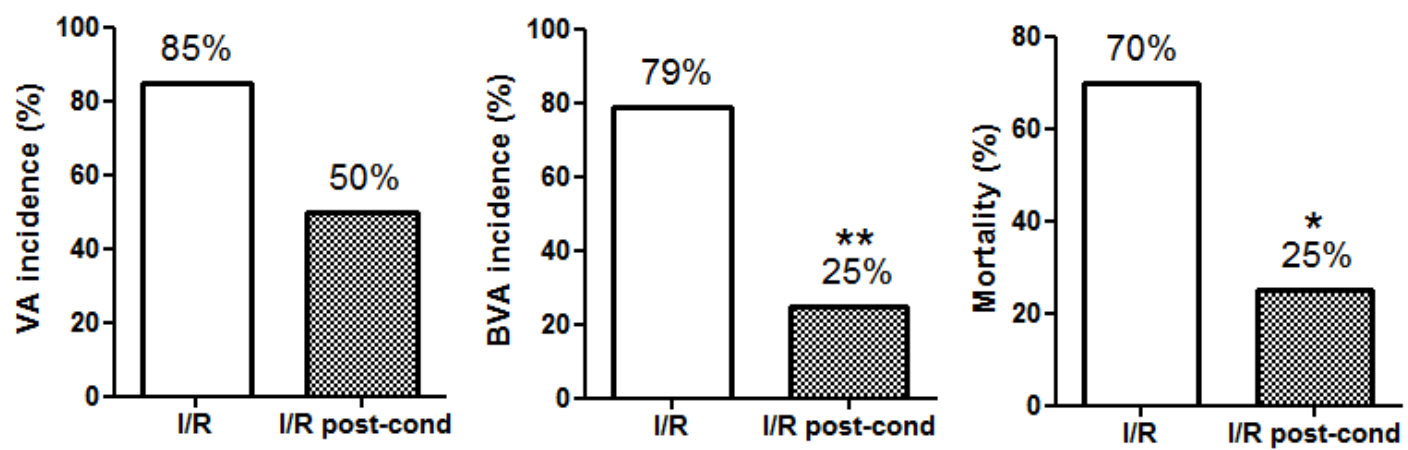

Figure 2 - Histograms representing percentages of incidence of VA and BVA and mortality in I/R and I/R + postCl groups. Statistical analysis were performed from Fisher's exact test $\left({ }^{*} p<0.05,{ }^{* *} p<0.005\right)$.

\section{Discussion}

The results obtained in this study showed that the incidence of $V A$ and $A V B$ and mortality in animals submitted to cardiac $\mathrm{I} / \mathrm{R}$ was reduce when animals were subjected to $\mathrm{preCl}$, and postCl. The preCl significantly reducing the incidence of $A V B$ and mortality in animals submitted to cardiac $I / R$ when compared with postCl.
Ischemic preconditioning (preCl) describes the protection afforded by brief periods (or periods) of ischemia against a subsequent longer lasting ischemic episode. This protection is typically measured as prevention against arrhythmias, reduction in the size of myocardial infarction or better recovery of the electrical and contractile function of the heart.

The preCl stimulates increased 
production of NO by myocardial cells, which in response activates intracellular signaling cascade that inhibits opening of mitochondrial permeability transition pore (MPTP), resulting in production of ATP and homeostasis of $\mathrm{Ca}^{2+}$ and $\mathrm{Na}^{+15}$. The $\mathrm{K}^{+} \mathrm{ATP}$-dependent mitochondrial (mKATP) channels present in the inner mitochondrial membrane are activate during preCl, increasing volume of mitochondrial matrix and oxidation of fatty acids ${ }^{16}$ with production of oxigen-reactive species (ROS) ${ }^{17}$.

The opening these channels involves the epsilon isoform of protein kinase C $(\mathrm{PKC} \varepsilon)^{18}$, preventing hyperpolarization of electrical potential of mitochondrial membrane ${ }^{19}$ avoiding accumulation of mitochondrial $\mathrm{Ca}^{2+}$, prolonged opening of MPTP, release of cytochrome $\mathrm{c}$ and apoptosis $\mathrm{s}^{20,21}$.

The cardioprotection afforded by $\mathrm{preCl}$ is mediate by combination of multiple endogenous mechanisms involving adrenergic receptors ( $\alpha 1$ e $\beta_{3}$ ), opioid receptor, bradykinin $\mathrm{B} 2$ receptor and adenosine receptor ${ }^{22}$. Found in our study that ischemic preCl reduce the incidence of cardiac arrhythmias and mortality by I/R. The preCl confers cardioprotection reducing the incidence of arrhythmias induced by $I / R^{23}$ in cardiomyocytes cultured and isolated hearts in different animal species ${ }^{24}$. Prior exposure for 1 to 2 cycles of ischemia (5 $\mathrm{min}$ ) and reperfusion (10 $\mathrm{min}$ ) reduced the incidence of ventricular fibrillation from $42 \%$ to $17 \%$ with 2 cycles and completely abolished this type of arrhythmia with 1 cycle in isolated hearts rabbits subjected to ischemia for $30 \mathrm{~min}$ followed by reperfusion for $45 \mathrm{~min}^{25}$.

Prior exposure of isolated hearts in male Wistar rats to one cycle of ischemia $(5 \mathrm{~min}$ ) and reperfusion (5 $\mathrm{min}$ ) reduced the number of premature ventricular beats, the incidence and duration of ventricular tachycardia in isolated hearts subjected to $30 \mathrm{~min}$ ischemia ${ }^{26}$. Kolettis et al. ${ }^{24}$ showed that prior exposure to 2 cycles of ischemia ( $5 \mathrm{~min})$, reperfusion $(5 \mathrm{~min})$ in
Wistar rats undergoing cardiac ischemia for 30 min and reperfusion for 24 hours significantly reduced the incidence of VA, mortality and myocardial lesion size ${ }^{24}$.

Experimental studies in different models of $I / R$ have shown that inhibitor of NO biosynthesis L-NAME, reduce cardioprotective response stimulated by $\mathrm{preCl}$, suggesting involvement of cellular signaling via NO/ cGMP/PKG response ${ }^{27}$. The signaling via NO/ cGMP/PKG pathway has a crucial role in excitation-contraction coupling and cellular $\mathrm{Ca}^{2+}$ homeostasis during I/R. This increase in NO/cGMP/PKG system activity is mediate by increased NOS activity induced by $\mathrm{preCl}^{28}$.

The increase in PKG activity stimulates opening of mKATP, decreasing mitochondrial $\mathrm{Ca}^{2+}$ overload, ROS production and prolonged opening of MPTP tomaintain ATP production ${ }^{29-32}$. As well as its application in the myocardium, ischemic preconditioning can also be induced by brief interruptions of blood flow to other organs, particularly skeletal muscle. Transient ischemia induced noninvasively by inflating a cuff on a limb, followed by reperfusion, helps reduce the damage caused to the myocardium by interruption of the coronary circulation. Remote ischemic preconditioning involves activation of humoral and/or neural pathways that open mitochondrial ATP-sensitive potassium channels in the myocardium and close mitochondrial permeability transition pores, making cardiomyocytes less vulnerable to ischemia-induced cell death ${ }^{33}$.

This cardioprotective mechanism is now being translated into clinical practice, with positive results in several clinical trials in coronary artery bypass surgery, surgical repair of abdominal aortic aneurysms, valve replacement surgery and percutaneous coronary intervention ${ }^{34-40}$.

In our study postCl reduce the incidence of cardiac arrhythmias and mortality caused by I/R. This procedure has been proposed as an 
important non-pharmacological experimental strategy to reduce area of injury produced by $1 / R^{41}$.

The postCl reduces incidence of arrhythmia and mortality in animal models of cardiac $\mathrm{I} / \mathrm{R}^{42}$. The postCl reversed sustained ventricular tachyarrhythmia and ventricular fibrillation preventing mortality of animals subjected to $1 / R^{43}$, and the application of 4 cycles of $\mathrm{I} / \mathrm{R}$ (20s each) immediately after regional ischemia for $5 \mathrm{~min}$ decreased the incidence of ventricular arrhythmias compared to control animals ${ }^{44}$.

Improvement of electrocardiographic parameters and myocardial perfusion through ischemic postCl ( 2 cycles of 90 s separated by 3 and $5 \mathrm{~min}$ ) in 17 patients who had suffered MI who underwent percutaneous coronary intervention $\mathrm{PCl}$ was observed for reperfusion therapy standard ${ }^{45}$.

In a study in which 30 patients admitted for coronary angioplasty for AMI underwent post- $\mathrm{Cl}$ (4 cycles of I/R 1 min each), there was reduction in release of creatine kinase, improves microvascular circulation and reduction of infarct size ${ }^{10}$.

In postCl interruption of reperfusion after 1 hour of coronary artery occlusion in canine model (3 cycles of $30 \mathrm{~s}$ reperfusion followed by $30 \mathrm{~s}$ ischemia) followed by reperfusion for $3 \mathrm{~h}$ reduced the size of cardiac infracted tissue ${ }^{46,47}$. Reducing size of infarcted area afforded by postCl has been observe in different species, including pigs, dogs, rabbits, mice and rats ${ }^{41}$.

The postCl performed within approximately less than $1 \mathrm{~h}$ of serious ischemia followed by reperfusions and occlusions of the coronary artery significantly reduced the QT dispersion and ventricular fibrillation associated with acute cardiac ischemia ${ }^{48}$.

Short periods of ischemia applied in early minutes of reperfusion reduced infarct size, endothelial dysfunction, accumulation of neutrophils, ROS generation and activated different signaling pathways for cell survival, including ERK1/2 (extracellular signal regulated protein kinase), PI3K-Akt (phosphatidylinositol 3-kinase) ${ }^{41}$ neuronal nitric oxide synthase $(\mathrm{nNOS})^{49}$ or preventing prolonged opening MPTP $^{50}$.

\section{Conclusion}

The cardiac preconditioning is more efficient than postconditioning to reduce the incidence of cardiac arrhythmias and mortality resulting from cardiac ischemia and reperfusion, conferring cardioprotection.

\section{References}

1. Rutledge T, Reis VA, Linke SE, Greenberg $\mathrm{BH}$, Mills PJ. Depression in heart failure a meta-analytic review of prevalence, intervention effects, and associations with clinical outcomes. J Am Coll Cardiol. 2006;48(8):1527-537. doi: 10.1016/j. jacc.2006.06.055.

2. Pantazi E, Bejaoui M, Folch-Puy E, Adam R, Roselló-Catafau J. Advances in treatment strategies for ischemia reperfusion injury. Expert Opin Pharmacother. 2016;8:1-11. doi: 10.1517/14656566.2016.1115015.

3. Frank A, Bonney M, Bonney S, Weitzel L, Koeppen M, Eckle T. Myocardial ischemia reperfusion injury: From basic science to clinical bedside. Semin Cardiothorac Vasc Anesth. 2012;16:123-32. doi: 10.1177/1089253211436350.

4. Bers DM. Calcium cycling and signaling in cardiac myocytes. Ann Rev Physiol. 2008;70:23-49. doi: 10.1146/annurev. physiol.70.113006.100455.

5. Xie LH, Weiss JN. Arrhythmogenic consequences of intracellular calcium waves. Am J Physiol Heart Circ Physiol. 2009;297(3):H997-1002. doi: 10.1152/ ajpheart.00390.2009.

6. Canty JM Jr, Suzuki G. Myocardial perfusion and contraction in acute ischemia and chronic ischemic heart disease. J Mol Cell Cardiol. 2012;52(4):822-31. doi: 10.1016/j. yjmcc.2011.08.019. 
7. Holley CT, Long EK, Lindsey ME, McFalls EO, Kelly RF. Recovery ofhibernatingmyocardium: what is the role of surgical revascularization? J Card Surg. 2015;30(2):224-31. doi: 10.1111/jocs.12477.

8. Kelle I, Akkoç $\mathrm{H}$, Uyar E, Erdinç M, Evliyaoğlu $O$, Sarıbaş S, Tunik S, Özoğul C. The combined effect of rosuvastatin and ischemicpre- or postconditioning on myocardial ischemiareperfusion injury in rat heart. Eur Rev Med Pharmacol Sci. 2015;19(13):2468-76. PMID: 26214784.

9. Wever $K E$, Hooijmans $C R$, Riksen NP, Sterenborg TB, Sena ES, Ritskes-Hoitinga $M$, Warlé MC.Determinants of the efficacy ofcardiacischemicpreconditioning: a systematic review and metaanalysis of animal studies. PLoS One. 2015;18;10(11):e0142021. doi: 10.1371/ journal.pone.0142021.

10.Staat P, Rioufol G, Piot C, Cottin Y, Cung TT, L'Huillier I, Aupetit JF, Bonnefoy E, Finet G, André-Fouët $X$, Ovize $M$. Postconditioning the human heart. Circulation. 2005;112(14):2143-8. doi: 10.1161/ CIRCULATIONAHA.105.558122.

11.Frohlich GM, Meier P, White SK, Yellon DM, Hausenloy DJ. Myocardial reperfusion injury: looking beyond primary $\mathrm{PCl}$. Eur Heart J. 2013;34:1714-24. doi: 10.1093/ eurheartj/eht090.

12.Vinten-Johansen J, Shi W. Perconditioning and postconditioning: current knowledge, knowledge gaps, barriers to adoption, and future directions. I Cardiovasc Pharmacol Ther. 2011;16(3-4):260-6. doi: $10.1177 / 1074248411415270$.

13.Tavares JG, Vasques ER, Arida RM, Cavalheiro EA, Cabral FR, Torres LB, Menezes-Rodrigues FS, Jurkiewicz A, Caricati-Neto A, Godoy CM, Gomes da Silva S. Epilepsy-induced electrocardiographic alterations following cardiac ischemia and reperfusion in rats. Braz J Med Biol Res. 2015;48(2):140-5. doi: 10.1590/1414-431X20144311.

14.Tavares JG, Menezes-Rodrigues FS, Vasques ER, Maia-Reis MC, Paula L, Luna-Filho B, Errante PR, Caricati-Neto A, Bergantin LB. A simple and efficient methodology for the study of cardioprotective drugs in animal model of cardiac ischemia-reperfusion. J Mol Imag Dyn. 2017;7:1. doi: 10.4172/21559937.1000133.
15. Halestrap AP, Clarke SJ, Khaliulin I. The role of mitochondria in protection of the heart by preconditioning. Biochim Biophys Acta. 2007;1767:1007-31. doi: 10.1016/j. bbabio.2007.05.008.

16.Grover GJ, Garlid KD. ATP-sensitive potassium channels: a review of their cardioprotective pharmacology. J Mol Cell Cardiol. 2000;32:677-95. doi: 10.1006/ jmcc.2000.1111.

17.Garlid KD. Opening mitochondrial KATP channel in the heart-what happens, and what does not happen. Basic Res Cardiol. 2000;95:275-9. PMID: 11005581.

18.Ohnuma Y, Miura T, Miki T, Tanno M, Kuno A, Tsuchida A, Shimamoto K. Opening of mitochondrial KATP channel occurs downstream of PKC- $\varepsilon$ activation in the mechanism of preconditioning. Am J Physiol Heart Circ Physiol. 2002;283:H440-7. doi: 10.1152/ajpheart.00434.2001.

19. Koretsune Y, Marban E. Mechanism of ischemic contracture in ferret hearts: relative roles of $\left[\mathrm{Ca}^{2+}\right]_{\text {, }}$ elevation and ATP depletion. Am J Physiol. 1990;258:H9-C16. doi: 10.1152/ajpheart.1990.258.1.H9.

20.Wang L, Cherednichenko G, Hernandez L, Halow J, Camacho SA, Figueredo V, Schaefer $\mathrm{S}$. Preconditioning limits mitochondrial $\mathrm{Ca}^{2+}$ during ischemia in rat hearts: role of K(ATP) channels. Am J Physiol. 2001;280:H2321-8. doi: 10.1152/ajpheart.2001.280.5.H2321.

21.Korge P, Honda HM, Weiss JN. Protection of cardiac mitochondria by diazoxide and protein kinase $\mathrm{C}$ : implications for ischemic preconditioning. Proc Natl Acad Sci USA. 2002;99:3312-7. doi: 10.1073/ pnas.052713199.

22. Abete $P$, Cacciatore F, Testa G, Della-Morte D, Galizia SD, Calabrese C, Cioppa A, Ferrara $\mathrm{N}$, Rengo $\mathrm{F}$. Ischemic preconditioning in the aging heart: from bench to bedside. Ageing Res Rev. 2010;9:53-162. doi: 10.1016/j. arr.2009.07.001.

23.Xie LH, Weiss JN. Arrhythmogenic consequences of intracellular calcium waves. Am J Physiol Heart Circ Physiol. 2009;297(3):H997-1002. doi: 10.1152/ ajpheart.00390.2009.

24. Kolettis TM, Vilaeti AD, Tsalikakis DG, Zoga A, Valenti M, Tzallas AT, Papalois A, Iliodromitis EK. Effects of pre- and postconditioning on arrhythmogenesis in the in vivo rat model. J 
Cardiovasc Pharmacol Ther. 2013;18(4):37685. doi: $10.1177 / 1074248413482183$.

25.Lukas A, Botsford MW. Cardioprotection induced by ischemic preconditioning in the mammalian heart: effects on arrhythmogenesis. Can J Physiol Pharmacol. 1997;75(4):316-25. PMID: 9196858.

26. Matejíková J, Ravingerová T, Pancza D, Carnická S, Kolár F. Mitochondrial KATP opening confers protection against lethal myocardial injury and ischaemia-induced arrhythmias in the rat heart via PI3K/Aktdependent and -independent mechanisms. Can J Physiol Pharmacol. 2009;87(12):105562. doi: 10.1139/Y09-100.

27.Schulz R, Ferdinandy P. Does nitric oxide signaling differ in pre-and postconditioning? Importance of S-nitrosylation vs. protein kinase $G$ activation. Free Radic Biol Med. 2013;54:113-5. doi: 10.1016/j. freeradbiomed.2012.10.547

28.Zaugg M, Schaub MC. Signaling and cellular mechanisms in cardiac protection by ischemic and pharmacological preconditioning. J Mus Res Cell Motil. 2003;24:219-49. PMID: 14609033.

29.Schultz JE, Qian YZ, Gross GJ, Kukreja RC.The ischemia-selective KATP channel antagonist, 5-hydroxydecanoate, blocks ischemic preconditioning in the rat heart. J Mol Cell Cardiol. 1997;29(3):1055-60. doi: 10.1006/ jmcc.1996.0358.

30.Cleveland JC Jr, Meldrum DR, Cain BS, Banerjee $A$, Harken AH. Oral sulfonylurea hypoglycemic agents prevent ischemic preconditioning in human myocardium. Two paradoxes revisited. Circulation. 1997;96(1):29-32. doi: 10.1161/01. CIR.96.1.29.

31.Kloner RA. No-reflow phenomenon: maintaining vascular integrity. J Cardiovasc Pharmacol Ther. 2011;16(3-4):244-50. doi: $10.1177 / 1074248411405990$.

32.Penna C, Perrelli MG, Pagliaro P. Mitochondrial pathways, permeability transition pore, and redox signaling in cardioprotection: therapeutic implications. Antioxid Redox Signal. 2013;18(5):556-99. doi: 10.1089/ars.2011.4459.

33. Costa JF, Fontes-Carvalho R, Leite-Moreira A. Pré-condicionamento isquémico remoto do miocárdio: dos mecanismos fisiopatológicos à aplicação na prática clínica. Rev Port Cardiol. 2013;32(11):893904. doi: 10.1016/j.repc.2013.02.012.

34.Succi JE, Gerola LR, Succi GM, Almeida RACF, Novais LSR, Rocha B.Ischemic preconditioning influence ventricular function in off-pump revascularization surgery. Arq Bras Cardiol. 2010;94(3):339-44. doi:doi.org/10.1590/ S0066-782X2010000300010.

35.Karami A, Khosravi MB, Shafa M, Azemati $\mathrm{S}$, Khademi S, Akhlagh SH, Maghsodi B. Cardioprotective effect of extended remote ischemic preconditioning in patients undergoing coronary artery bypass grafting: A randomized clinical trial. Iran J Med Sci. 2016;41(4):265-74. PMID: 27365547.

36. Baumert J-H, Roehl $A B$, Funcke $S$, Hein $M$. Xenon protects left ventricular diastolic function during acute ischemia, less than ischemic preconditioning. Med Gas Res. 2016;6(3):130-7. doi: 10.4103/20459912.191358.

37.Lotfi AS, Eftekhari H, Atreya AR, Kashikar A, Sivalingam SK, Giannoni M, Visintainer $P$, Engelman D.Randomized controlled trial of remote ischemicpreconditioning and atrial fibrillation in patients undergoingcardiac surgery. World J Cardiol.2016;26;8(10):615-22. doi: 10.4103/2045-9912.191358.

38. Garcia S, Rector TS, Zakharova M, Herrmann RR, Adabag S, Bertog S, Sandoval Y, Santilli $S$, Brilakis ES, McFalls EO. Cardiac remote ischemic preconditioning prior to elective vascular surgery (CRIPES): A prospective, randomized, sham-controlled phase II clinical trial. J Am Heart Assoc. 2016;5(10). pii: e003916. doi: 10.1161/JAHA.116.003916.

39. Kosiuk J, Milani R, Ueberham L, Uhe T, Stegmann C, Hindricks G, Bollmann A. Effect of remote ischemic preconditioning on electrophysiological and biomolecular parameters in nonvalvular paroxysmal atrial fibrillation (RIPPAF Study): rationale and study design of a randomized, controlled clinical trial. Clin Cardiol. 2016;39(11):6315. doi: $10.1002 / c l c .22584$.

40.Cheung CX, Healy DA, Walsh SR. Remote preconditioning and cardiac surgery: regrouping after remote ischemic preconditioning for heart surgery (RIPHeart) and effect of remote ischemic preconditioning on clinical outcomes in patients undergoing coronary artery 
bypass surgery (ERICCA). J Thorac Dis. 2016;8(3):E197-9. doi: 10.21037/ jtd.2016.01.81.

41.Vinten-Johansen J, Zhao ZQ, Zatta AJ, KinH, Halkos ME, Kerendi F. Postconditioning -A new link in nature's armor against myocardial ischemia-reperfusion injury. Basic Res Cardiol. 2005;100(4):295-310. doi: 10.1007/s00395-005-0523-x.

42.Pena C, Mancardi D, Raimondo S, Geuna S, Pagliaro $\mathrm{P}$. The paradigm of postconditioning to protect the heart. J Cell Mol Med. 2008;12(2):435-58. doi: 10.1111/j.15824934.2007.00210.x.

43.Galagudza M, Kurapeev D, Minasian S, Valen G, Vage J. Ischemic postconditioning: brief ischemia during reperfusion converts persistent ventricular fibrillation into regular rhythm. Eur J Cardiothorac Surg. 2004;25(6):1006-10. doi: 10.1016/j. ejcts.2004.02.003.

44. Ioner RA, Dow J, BhandariA. Postconditioning markedly attenuates ventricular arrhythmias after ischemia-reperfusion. J Cardiovasc Pharmacol Ther. 2006;11(1):55-63. doi: $10.1177 / 107424840601100105$.

45.Laskey WK. Brief repetitive balloon occlusions enhance reperfusion during percutaneous coronary intervention for acute myocardial infarction: a pilot study. Catheter Cardiovasc Interv. 2005;65(3):3617. doi: $10.1002 /$ ccd.20397

46.Zhao ZQ, Corvera JS, Halkos ME, Kerendi F,Wang NP,Guyton RA, Vinten-Johansen J. Inhibition of myocardial injury by ischemic post conditioning during reperfusion: comparison with ischemic preconditioning. Am J Physiol Heart Circ Physiol. 2003;285:H579-88. doi: 10.1152/ ajpheart.01064.2002.

47. Halkos ME, Kerendi F, Corvera JS, Wang NP, Kin H, Payne CS, Sun HY, Guyton RA, Vinten-Johansen J, Zhao ZQ. Myocardial protection with postconditioning is not enhanced by ischemic preconditioning. Ann Thorac Surg. 2004;78:961-9. doi: 10.1016/j. athoracsur.2004.03.033.

48. Okishige K, Kanda S, Shimura T, Kurabayashi $M$, Ueshima $D$, Miwa $N$, Sugiyama $K$, Aoyagi $\mathrm{H}$, Yoshimura K, Yanagi H, Azegami $\mathrm{K}$. Clinical study of the electrophysiological effects of ischemic postconditioning in patients with acute myocardial infarctions. J Cardiology. 2011;58:137-42. doi: 10.1016/j. jjcc.2011.05.002.

49. Hu L, Wang J, Zhu H, Wu X, Zhou L, Song $Y$, Zhu S, Hao M, Liu C, Fan Y, Wang $Y$, Li Q. Ischemic postconditioning protects the heart against ischemia-reperfusion injury via neuronal nitric oxide synthase in the sarcoplasmic reticulum and mitochondria. Cell Death and Disease. 2016;7:e2222. doi: 10.1038/cddis.2016.108.

50.Tsang A, Hausenloy DJ, Mocanu MM, Yellon DM. Postconditioning: a form of "modified reperfusion" protects the myocardium by activating the phosphatidilinositol 3-kinaseAkt pathway. Circ Res. 2004;95:230-2. doi: 10.1161/01.RES.0000138303.76488.fe.

\section{Correspondence:}

Prof. Dr. Afonso Caricati-Neto

Laboratório de Farmacologia Autonômica e Cardiovascular, UNIFESP

Rua Pedro de Toledo, 699/7ㅇ andar

04039-032 São Paulo-SP Brasil

caricatineto@gmail.com

Received: Mar 23, 2018

Review: May 25, 2018

Accepted: June 24, 2018
Conflict of interest: none

Financial sources: CNPq, FAPESP, and CAPES 